Received 00th January 20xx, Accepted 00th January 20xx DOI: $10.1039 / \times 0 \times x 00000 x$

\title{
Photoreduction of Triplet Thioxanthone Derivative by Azolium Tetraphenylborate: a Way to Photogenerate N-Heterocyclic Carbenes
}

Thi Kim Hoang Trinh, ${ }^{\mathrm{a}, \mathrm{b}}$ Fabrice Morlet-Savary, ${ }^{\mathrm{a}, \mathrm{b}}$ Julien Pinaud, ${ }^{\mathrm{c}}$ Patrick Lacroix-Desmazes, ${ }^{\mathrm{c}}$ Corine Reibel, ${ }^{c}$ Cécile Joyeux, ${ }^{d}$ Didier Le Nouen, ${ }^{d}$ Rémi Métivier, ${ }^{e}$ Arnaud Brosseau, ${ }^{e}$ Valérie Héroguez, ${ }^{f}$ Abraham Chemtob ${ }^{* a, b}$

\begin{abstract}
Although $\mathrm{N}$-heterocyclic carbenes (NHCs) have brought profound changes in catalytic organic synthesis, their generation generally requires inert atmosphere and harsh conditions. To overcome these limitations, an air-stable NHC photogenerator has been developed involving two mild components: 1,3-bis(mesityl)imidazolium tetraphenylborate $\left(\mathrm{IMes}^{+} \mathrm{BPh}_{4}{ }^{-}\right)$and electronically excited isopropylthioxanthone (ITX). In this study, the photochemical mechanism is investigated through the accurate identification of the transient species and photoproducts. Electron transfer reaction between the excited triplet state of ITX and $\mathrm{BPh}_{4}{ }^{-}$is demonstrated as being the primary photochemical step. Nanosecond laser spectroscopy shows an efficient quenching and the formation of the expected ITX radical anion. The oxidized borane species is not observed, suggesting that this short-lived species could dissociate very rapidly to give phenyl radical successfully identified using electron paramagnetic resonance - and triphenylborane. As regards the final photoproducts, ${ }^{1} \mathrm{H}$ and ${ }^{13} \mathrm{C}$ NMR spectroscopy support the formation of the targeted NHC, 1,3-bis(2,4,6-trimethylphenyl)imidazol-2-ylidene (IMes), suggesting the occurrence of a subsequent proton transfer reaction between ITX radical anion and imidazolium cation $\left(\mathrm{IMesH}^{+}\right)$. Gas chromatography-mass spectrometry reveals three other products: biphenyl, isopropylthioxanthene and ITX. Their formation can be reconciled with a 2-step mechanism of photoinduced electron/proton transfer reactions. ${ }^{11} \mathrm{~B} N M R$ spectroscopy demonstrates that the main organoboron photoproduct is diphenylborinic acid formed by oxidation of $\mathrm{BPh}_{3}$. Due to its Lewis acidity, $\mathrm{Ph}_{2} \mathrm{BOH}$ can react with IMes to yield an NHC-boron adduct.
\end{abstract}

\section{Introduction}

Of high importance in photochemistry are arylborates, which are four-coordinate boron compounds bearing a tetrahedral geometry, a formal negative charge, and at least one aryl substituent. Although their photochemical reactivity has been studied since the late $1970 \mathrm{~s},{ }^{1,2}$ progress in this field has been made at the cost of intense debates, ${ }^{3}$ and many unknowns still remain. ${ }^{4}$ Photoreactivity of arylborates is organized around two major types of reactions (Figure 1): 1/ direct photolysis and 2 / photoinduced electron transfer (PET), in this latter case, the borate anion acts as one electron reducing agent. Recently, other reactions such as photochromic isomerization or photoelimination were described for arylborate molecules with an N,C- or a C,C-chelate backbone. ${ }^{5}$

a. Institut de Science des Matériaux de Mulhouse, IS2M UMR 7361 CNRS, Université de Haute-Alsace, Mulhouse, France.

${ }^{b .}$ Université de Strasbourg, Strasbourg, France.

c. ICGM, Université de Montpellier, CNRS, ENSCM, Montpellier, France.

d. Laboratoire d'Innovation Moléculaire et Applications, LIMA, Université de HauteAlsace, France.

e. Laboratoire PPSM, ENS Cachan, CNRS, Université Paris-Saclay, 94235, Cachan,

France.

f. Université de Bordeaux, CNRS, Bordeaux INP, LCPO, UMR 5629, F-33600, Pessac,

France.

+ Electronic Supplementary Information (ESI) available. See

DOI: $10.1039 / x 0 \times x 00000 x$
- Photolysis upon exposure to $254 \mathrm{~nm}$ irradiation (route 1) was focused on tetraarylborate compounds such as $\mathrm{NaBPh}_{4}$. The most accepted mechanism involves a di- $\pi$-borate rearrangement leading to a three-membered biradical anion, evolving towards a more stable borirane anion isomer. Most studies on direct irradiation attempted to identify photoproducts (biphenyl, 1-phenyl-cyclohexadiene mostly) and elucidate photochemical mechanism. ${ }^{1,6,7}$ Its utility in preparative photochemistry was demonstrated only recently.

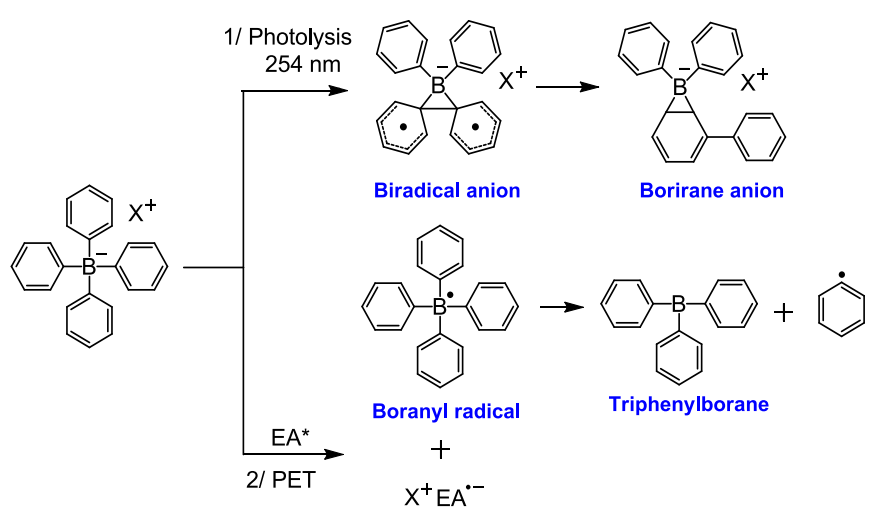

Figure 1. Photochemical reactivity of arylborate species. Route 1 is based on direct photolysis while Route 2 is a photoinduced electron transfer (PET) involving an electron acceptor (EA) sensitizer. The asterisk designates an excited state. 
Observing that intermediate anion species could abstract acidic protons from water and alcohol, ${ }^{7,8}$ Sun et al. proposed in 2008 a tetraphenylborate salt containing as cation the conjugated acid of a nitrogen base $\left(\mathrm{BH}^{+}\right)$such as bicyclic guanidine $\operatorname{TBD}\left(\mathrm{TBDH}^{+}\right){ }^{6}$ The base was photogenerated through photoinduced proton abstraction of $\mathrm{BH}^{+}$during the photolysis at $254 \mathrm{~nm}$. For example, $\mathrm{TBDH}^{+} \mathrm{BPh}_{4}{ }^{-}$was used as photobase generator (PBG) for the organocatalyzed ringopening polymerization of cyclic esters ${ }^{6}$ or thiol-epoxy polymerization. ${ }^{9}$ Several authors added an aryl ketone derivative to extend absorption to near UV-Vis range via a supposed triplet-triplet energy transfer. ${ }^{10-13}$

- Due to their relatively low oxidation potential, ${ }^{14}$ arylborates such as $\mathrm{Ph}_{4} \mathrm{~B}^{-}$or triarylalkylborate salts $\left(\mathrm{Ph}_{3} \mathrm{BR}^{-}\right)$ were also used as electron donor in inter- and intra-PET reactions (route 2 ) with cationic or neutral electron acceptor (EA) sensitizers such as carbocyanine, ${ }^{15}$ fullerene, ${ }^{16}$ coumarine, ${ }^{17}$ fluorone, ${ }^{18}$ benzophenone derivatives. ${ }^{19}$ A boranyl radical is formed, which in turn undergoes rapid cleavage yielding a triphenylborane and a phenyl (or alkyl) radical. Only alkyl radicals have been applied for initiation of radical polymerizations, ${ }^{17}$ or alkylation of the EA. ${ }^{20}$

Recently, we proposed another application for photoinitiated oxidation of arylborates, the photogeneration of $\mathrm{N}$-heterocyclic carbene (NHC) from an azolium arylborate salt $\left(\mathrm{NHCH}^{+} \mathrm{BPh}_{4}{ }^{-}\right)$(Figure 2). ${ }^{21}$ When paired with an EA sensitizer such as isopropylthioxanthone (ITX), an electron transfer from the borate $\left(\mathrm{Ph}_{4} \mathrm{~B}^{-}\right)$to the excited triplet state of ITX $\left({ }^{3} \mathrm{ITX}^{*}\right)$ may occur as described above. Unlike the previous case, the azolium cation $\left(\mathrm{NHCH}^{+}\right)$enables a subsequent step of proton abstraction with ITX radical anion ITX ${ }^{--}(\mathbf{1})$ to take place, yielding the expected free NHC (2). ${ }^{21}$ Our recent investigations proved that it was possible to form IMes and its saturated analogue SIMes, the two most employed NHCs. ${ }^{21}$ The utility of this two-component NHC photogenerator $\mathrm{NHCH}^{+} \mathrm{BPh}_{4}^{-} / \mathrm{ITX}$ was also demonstrated in photopolymerization reactions to form polyurethane, polyester and polynorbornene. ${ }^{22}$ Indeed, although NHCs have brought profound changes in catalytic organic synthesis, ${ }^{23-25}$ they generally require inert atmosphere and harsh conditions for their generation. As a result, an air-stable system based on mild components, able to generate NHC on demand and on simple UV exposure has the potential to significantly simplify implementation of the broad spectrum of NHC-catalyzed reactions. While it is true that thermally latent $\mathrm{NHC}$ precursors also exist, ${ }^{26,27}$ photochemically produced NHCs have net advantages including ambient temperature reaction, thermal stability and the possibility to finely tune NHC concentration upon adjusting the energetic dosage.

Though the mechanistic hypothesis for photoreduction of thioxantone derivative by arylborates is basically acceptable, conclusive evidences in support of a coupled electron transfer/proton abstraction are required. With exception of the photogenerated NHC molecule (2), little is known about the transient species $-{ }^{3} \mathrm{ITX}^{*}, \mathrm{ITX}^{\boldsymbol{0}^{-}}(\mathbf{1}), \mathrm{ITXH}^{\bullet}(\mathbf{3}), \mathrm{Ph}_{4} \mathrm{~B}^{\bullet}(\mathbf{4}), \mathrm{Ph}^{\bullet}$ (5) - which are supposed to form and the other putative products such as $\mathrm{Ph}_{3} \mathrm{~B}(6)$ and the various thioxanthone derivatives. To provide conclusive evidences in support of our mechanism, it is important to clearly establish the identity of transient species and photoproducts. The structure of the organoboron compound(s) formed is particularly important given $\mathrm{BPh}_{3}$ is likely to form ate-complexes with $\mathrm{NHCs}$, with strong implications for carbene reactivity. ${ }^{28}$ Indeed, trivalent boron species typically have Lewis acid characteristics, while NHCs behave as Lewis base. Motivated by this situation, this paper investigates the identity of transient species and photoproducts generated by the irradiation of 1,3bis(mesityl)imidazolium tetraphenylborate $\left(\mathrm{IMesH}^{+} \mathrm{BPh}_{4}{ }^{-}\right.$, Figure 2) with ITX to form the NHC 1,3-bis(mesityl)imidazol-2ylidene (IMes). To this purpose, a range of techniques was used: nanosecond laser spectroscopy and electron paramagnetic resonance (EPR) for the detection of the transient species, as well as gas chromatography-mass spectrometry (GC-MS) and ${ }^{11} B$ NMR spectroscopy for the identification of the photoproducts.

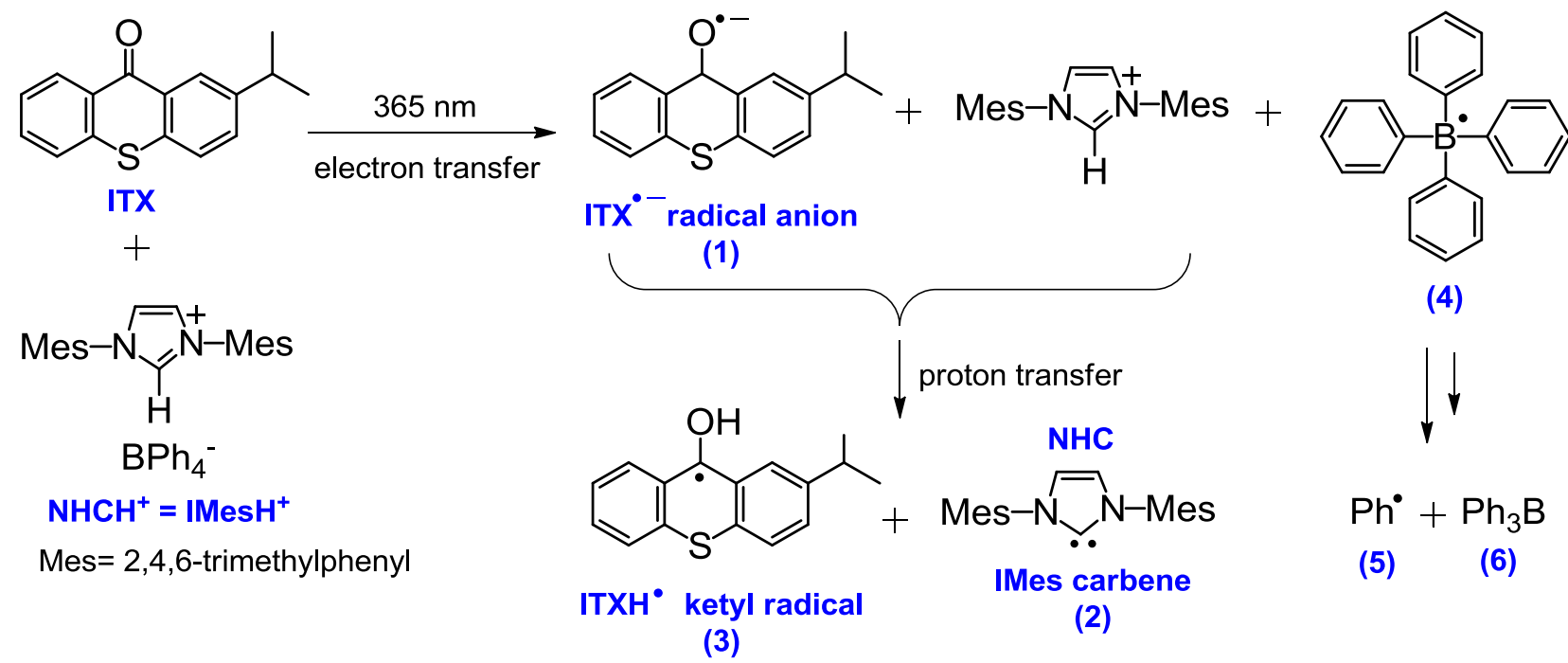

Figure 2. Photochemical pathway for the generation of $\mathrm{NHC}$ from a mixture of $\mathrm{NHCH}^{+} \mathrm{BPh}_{4}{ }^{-}$and ITX. 


\section{Experimental}

\section{Materials}

1,3-Bis(2,4,6-trimethylphenyl)imidazolium

chloride

$\left(\mathrm{IMesH}^{+} \mathrm{Cl}^{-}, 98.0 \%, \mathrm{TCl}\right)$, sodium tetraphenylborate $\left(\mathrm{NaBPh}_{4}\right.$ $99.5 \%, \mathrm{TCl}$ ), N-tert-butyl- $\alpha$-phenylnitrone (PBN, $98.0 \%, \mathrm{TCl}$ ), diphenyl(2,4,6-trimethylbenzoyl)phosphine oxide (TPO, $98 \%$, $\mathrm{TCl}$ ), 2-isopropylthioxanthone (ITX, analytical standard, Aldrich), 1,3-bis(2,4,6-trimethylphenyl)imidazol-2-ylidene (IMes, 97\%, Aldrich) and carbon disulfide $\left(\mathrm{CS}_{2}\right.$, anhydrous, Aldrich) were used as received unless otherwise mentioned. Acetonitrile- $d_{3}\left(\mathrm{ACN}-d_{3}, 99.8 \% \mathrm{D}\right.$, Aldrich), tetrahydrofuran- $d_{8}$ (THF- $d_{8}, 99.5 \% \mathrm{D}$, Eurisotop), acetonitrile (ACN, HPLC grade, VWR) and ethanol (EtOH, HPLC grade, VWR) were dried over 4 Å molecular sieves before use.

\section{Synthesis of $\mathrm{IMesH}^{+} \mathrm{BPh}_{4}^{-}$}

The $\mathrm{IMesH}^{+} \mathrm{BPh}_{4}{ }^{-}$was synthesized as described previously. ${ }^{21}{ }^{1} \mathrm{H}$ NMR (300 MHz, THF- $\left.d_{8}\right)$, IMesH $\mathrm{IMPh}_{4}{ }^{-}: \delta_{\mathrm{ppm}}$ : $2.03\left(\mathrm{~s}, 12 \mathrm{H}, 4 \times 0-\mathrm{ArCH}_{3}\right), 2.37\left(\mathrm{~s}, 6 \mathrm{H}, 2 \times p-\mathrm{ArCH}_{3}\right), 6.62-$ $6.66(\mathrm{t}, 4 \mathrm{H}, J=6 \mathrm{~Hz}, 4 \times \mathrm{ArH}), 6.75-6.80(\mathrm{t}, 8 \mathrm{H}, J=7.5 \mathrm{~Hz}, 8 \times$ $\mathrm{ArH}), 7.13(\mathrm{~s}, 4 \mathrm{H}, 4 \times \mathrm{ArH}), 7.15(\mathrm{~s}, 2 \mathrm{H}, 2 \times \mathrm{NCH}) 7.22-7.26$ (br, $8 \mathrm{H}, 2 \times 8 \times \mathrm{ArH})$, and $8.70(\mathrm{~s}, 1 \mathrm{H}, \mathrm{NCHN})$.

\section{Characterization methods}

Nanosecond laser spectroscopy. All nanosecond timeresolved transient absorption spectra were performed in a 1 $\mathrm{cm}$ optical path length and monitored by Edinburgh Instruments LP920 laser flash photolysis spectrometer. The solutions were excited at $90^{\circ}$ from the probe beam by a $Q$ switched nanosecond Nd/YAG laser $\left(\lambda_{\text {exc }}=355 \mathrm{~nm}, 8 \mathrm{~ns}\right.$ pulse duration; energy reduced down to $5 \mathrm{~mJ}$ per pulse from Continuum (Surelite II- 10). A filter was used to remove the residual excitation light at $355 \mathrm{~nm}$ (Schott GG385). As preliminary step, all acetonitrile solutions were purged with nitrogen for $5 \mathrm{~min}$ prior to measurement. The decay of the triplet-triplet state absorption of ITX $\left(1 \times 10^{-4} \mathrm{M}\right)$ at $600 \mathrm{~nm}$ was measured and follows a first-order kinetics. The temporal change of triplet concentration $\left[{ }^{3} \mathrm{ITX}^{*}\right]$ can be represented in equation (1):

$$
\left[{ }^{3} \mathrm{ITX}^{*}\right](\mathrm{t})=\left[{ }^{3} \mathrm{ITX}^{*}\right](0) \times e^{-t / \tau_{0}}
$$

where $\tau_{0}$ is the lifetime of the ITX triplet without quencher.

$$
\operatorname{Abs} .(\mathrm{t}, 600 \mathrm{~nm})=\operatorname{Abs} .(0,600 \mathrm{~nm}) \times e^{-t / \tau_{0}}
$$

Exponential fitting of the experimental decay Abs. (t, 600 $\mathrm{nm}$ ) provides $\tau_{0}$ (Equation (2)). In presence of a triplet quencher $\left(\mathrm{IMesH}^{+} \mathrm{BPh}_{4}{ }^{-}, \mathrm{NaBPh}_{4}\right.$ or $\left.\mathrm{IMesH}^{+} \mathrm{Cl}^{-}\right)$, a pseudo-firstorder kinetic equation can be applied to extract a triplet lifetime $\tau$ that depends on quencher concentration [Q]. Note that all the triplet lifetimes were determined by using a double exponential equation in the time range $0-40 \mu$ s the longer time-constant being due to the formation of the ITX radical anion at the monitored wavelength. By measuring $\tau$ at different [Q], the quenching rate constants, $k_{\mathrm{q}}$, can be obtained by the linear plot based on the Stern-Volmer equation (3). ${ }^{29}$

$$
\tau^{-1}=\tau_{0}^{-1}+k_{q}[\mathrm{Q}]
$$

Electron paramagnetic resonance (EPR). EPR measurements were performed with a Bruker Elexsys E500 spectrometer with $\mathrm{X}$ band frequency in continuous wave (around $9.8 \mathrm{GHz}$ ) at room temperature. Spectra were recorded with a modulation amplitude of $1 \mathrm{G}$, a modulation frequency of $100 \mathrm{kHz}$ and a microwave power of $\sim 2 \mathrm{~mW}$. Both Bruker WIN-EPR and SimFonia software were used to note the spectra and carry out the simulation afterwards. In a typical experiment, an acetonitrile solution $(1 \mathrm{~mL})$ containing $\mathrm{IMesH}^{+} \mathrm{BPh}_{4}{ }^{-}$(9.18 mg, 5 equiv.), ITX (1.27 mg, 3 equiv.) and PBN (0.54 mg, 1 equiv.) was degassed prior to transfer into an aqueous EPR cell. The cell was irradiated for different times (0 $\mathrm{s}, 30 \mathrm{~s}$ and $60 \mathrm{~s}$ ) with a $365 \mathrm{~nm}$ LED light-guide (LC-L1V3, Hamamatsu, $65 \mathrm{~mW} \cdot \mathrm{cm}^{-2}$ ) then an EPR spectrum was acquired.

${ }^{1} \mathrm{H} N M R$ and ${ }^{13} \mathrm{C}$ NMR spectroscopy. All ${ }^{1} \mathrm{H}$ NMR and ${ }^{13} \mathrm{C}$ NMR spectra were recorded in appropriate deuterated solvents with tetramethylsilane (TMS) as the internal reference on a Varian Merury $300 \mathrm{MHz}$. In a typical measurement, $\mathrm{IMesH}^{+} \mathrm{BPh}_{4}{ }^{-}$(9.18 $\mathrm{mg}, 0.015 \mathrm{mmol}, 3$ equiv.) and ITX (1.27 mg, $0.005 \mathrm{mmol}, 1$ equiv.) were charged into a borosilicate NMR tube. The mixture was dissolved in $0.3 \mathrm{~mL}$ of acetonitrile- $d_{3}\left(0.03 \mathrm{M}\right.$, relative to $\left.\mathrm{IMesH}^{+} \mathrm{BPh}_{4}{ }^{-}\right)$. Before exposure to a $365 \mathrm{~nm}$ LED light spot during $5 \mathrm{~min}$ (see details in previous section), the NMR tube was capped with a rubber septum and degassed with $\mathrm{N}_{2}$. The as-irradiated tube was then analyzed by ${ }^{1} \mathrm{H}$ NMR. Excess amount of $\mathrm{CS}_{2}(0.02 \mathrm{~mL})$ was added subsequently into the tube. It caused a sudden color change from yellow to red followed by a gradual precipitation. The suspension media was kept for $24 \mathrm{~h}$, and the solid was collected by vacuum filtration and air dried for $24 \mathrm{~h} .{ }^{1} \mathrm{H}$ NMR and ${ }^{13} \mathrm{C}$ NMR measurements were performed in DMSO- $d_{6}$ to confirm the formation of the IMes- $\mathrm{CS}_{2}$ zwitterion adduct.

${ }^{11} B$ NMR spectroscopy. All ${ }^{11} \mathrm{~B}$ NMR were recorded in THF$d_{8}$ with $\mathrm{BF}_{3} . \mathrm{Et}_{2} \mathrm{O}$ as the internal reference on a Varian Bruker Avance NEO $500 \mathrm{MHz}$. All solutions were prepared under argon using a glove box technique. Prior to utilization, quartz NMR tubes were dried under vacuum overnight at $80^{\circ} \mathrm{C}$. The THF- $d_{8}$ solvent was dried over molecular sieves. 
Gas chromatography-mass spectrometry (GC-MS). The GC instrument is a Shimadzu GC-2010 model completed with the QP-2010 mass spectrometer system. Helium is the gas vector, used at the constant linear velocity of $25 \mathrm{~cm} \cdot \mathrm{s}^{-1}$. The sample was injected into a Supelco ${ }^{\circledR}$ BP-X5 column $(0.15 \mathrm{~mm}$ of diameter, $25 \mathrm{~m}$ of length and $0.25 \mu \mathrm{m}$ of film thickness) by using split mode with a ratio of $75: 25$. The temperature of the injector is maintained at $330^{\circ} \mathrm{C}$. The column temperature was heated from $70^{\circ} \mathrm{C}$ to $340^{\circ} \mathrm{C}$ in two subsequent steps: the first heating state to $250^{\circ} \mathrm{C}$ with heating rate of $15^{\circ} \mathrm{C} \cdot \mathrm{min}^{-1}$ and the second to $340^{\circ} \mathrm{C}$ at the rate of $4^{\circ} \mathrm{C} \cdot \mathrm{min}^{-1}$. Then, the sample was ionized using an electronic ionization source heated at $200^{\circ} \mathrm{C}$. The mass spectrum was recorded from $4 \mathrm{~min}$ to end of the program with scan mode from $50 \mathrm{~m} / \mathrm{z}$ to $600 \mathrm{~m} / \mathrm{z}$. Mass Spectra of each peak were compared with spectra of NIST05 and NIST05s databases to identify compounds. In a typical experiment, $2 \mathrm{~mL}$ of acetonitrile solution including $\mathrm{IMesH}^{+} \mathrm{BPh}_{4}^{-}(1.71 \mathrm{mg}, 0.003 \mathrm{mmol}, 3$ equiv.) and ITX $(0.24$ $\mathrm{mg}, 0.001 \mathrm{mmol}, 1$ equiv.) were placed into a UV quartz cuvette (1 cm optical path) and closed by a rubber septum. The cuvette was degassed with $\mathrm{N}_{2}$ during 5 min then immediately exposed to a $365 \mathrm{~nm}$ LED spot light $\left(65 \mathrm{~mW} \cdot \mathrm{cm}^{-2}\right)$ for $5 \mathrm{~min}$ while keeping the stirring. Finally, the irradiated solution was transfer into Agilent $2 \mathrm{~mL}$ glass vial with a screw top (PTFE septum) under inert condition for GC-MS analysis.

\section{Results and discussion}

\section{Assignment of transient species}

\section{Nanosecond laser spectroscopy}

To identify the intermediate species formed in the 2component system ITX/IMesH ${ }^{+} \mathrm{BPh}_{4}^{-}$(Figure 2), excitation transfer reactions of ITX with different quenchers were recorded by means of a nanosecond laser spectroscopy. Laser flash exposure was performed at $355 \mathrm{~nm}$ in deaerated and anhydrous acetonitrile, where only the sensitizer (ITX) absorbs the light. Given the short lifetime of ITX singlet state as well as its high intersystem crossing quantum yield, ${ }^{30,31}$ ITX is assumed to interact mainly via its triplet state. As can be seen in Figure 3a, the transient absorption spectra of ITX alone shows an absorption maximum at $630 \mathrm{~nm}$, fully consistent with the ITX triplet $\left({ }^{3} \mathrm{ITX}^{*}\right)$ in acetonitrile reported in the literature. ${ }^{29,30,32-34}$ Slow decrease of the transient absorption was attributed to the deactivation process of the ${ }^{3} \mathrm{ITX} *$ with a lifetime of $5.7 \mu \mathrm{s}$ at an initial ITX concentration of $10^{-4} \mathrm{M}$. To study the effect of the azolium cation, the reactivity of the triplet state was evaluated in presence of $\mathrm{IMesH}^{+} \mathrm{Cl}^{-}$since no quenching is expected from $\mathrm{Cl}^{-}$anion. ${ }^{35}$ The absorption at 630 $\mathrm{nm}$ was weakly quenched when this imidazolium salt was added to a deoxygenated solution of ITX. A low rate constant $\left(4.7 \times 10^{6} \mathrm{M}^{-1} \mathrm{~s}^{-1}\right)$ was determined by constructing a SternVolmer plot of the triplet lifetime as a function of [ $\left.\mathrm{IMesH}^{+} \mathrm{Cl}^{-}\right]$, with the triplet being monitored at $600 \mathrm{~nm}$ (see experimental section for details). A typical decay experimental trace for the triplet decay of ITX in presence of $\mathrm{IMesH}^{+} \mathrm{Cl}^{-}$is given in Figure 4 (trace a), showing clean first-order kinetics. The existence of
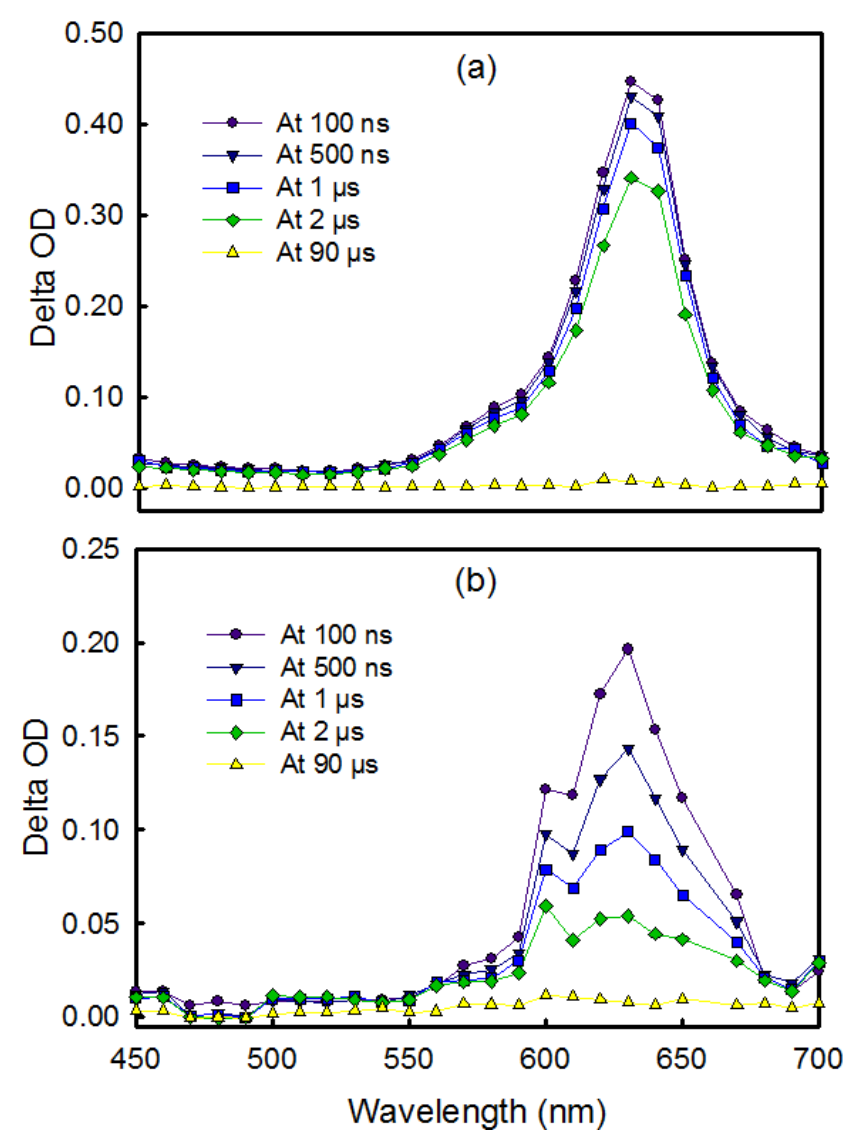

Figure 3. Transition absorption spectra of: (a) $[\mathrm{ITX}]=10^{-4} \mathrm{M}$ and (b) ITX/NaBPh $4=6 \times$ $10^{-3} \mathrm{M}$ for $100 \mathrm{~ns}-90 \mu$ s delay time in $\mathrm{N}_{2}$-saturated acetonitrile with excitation wavelength at $355 \mathrm{~nm}$. Delta OD is a change in optical density.

very weak interactions is consistent with the fact that photooxidation of ${ }^{3} \mathrm{ITX}^{*}$ by $\mathrm{IMesH}^{+}$is thermodynamically unfavorable $\left(\triangle \mathrm{G}_{\mathrm{et}}=+0.74 \mathrm{eV}\right)^{21}$ and that the triplet energy transfer between ITX $\left(E_{\mathrm{T}}=2.77 \mathrm{eV}\right)$ and $\mathrm{IMesH}^{+}\left(\mathrm{E}_{\mathrm{T}}=3.34 \mathrm{eV}\right)$ exhibits a fairly endothermic character (Fig. S1 in Supporting Information). It can thus be concluded that the azolium cation plays a minor role in the primary photochemical reaction.

Similarly, triplet quenching experiment was carried out with $\mathrm{NaBPh}_{4}$ to investigate the specific role of the tetraarylborate anion given that $\mathrm{Na}^{+}$cannot quench or donate proton. As can be seen in Figure $\mathbf{4}$ (trace b), the decay rate was much faster, illustrating the more efficient quenching of ${ }^{3} \mathrm{ITX}^{*}$ by $\mathrm{BPh}_{4}{ }^{-}$. Additionally, it can be noticed that the decay trace does not return to zero in this case; deviation to first order kinetics was attributed to the fact that the triplet absorption probably overlaps with another species. To clarify this point, Figure $\mathbf{3} \mathbf{b}$ shows the temporal evolution of the transient absorption spectrum of ITX/NaBPh ${ }_{4}$. After $100 \mathrm{~ns}$, it seems that the narrow $630 \mathrm{~nm}$ peak due to triplet absorption has disappeared and has been replaced by a new broad absorption in the region of $560-680 \mathrm{~nm}$. Subsequent spectra show the slow decay of this broad peak. We hypothesized that this transient species could be the radical anion $\mathrm{ITX}^{\boldsymbol{0}^{-}}$ generated after photoreduction of ${ }^{3} \mathrm{ITX}^{*}$ by $\mathrm{BPh}_{4}{ }^{-}$. To support our assignment, we rely first on the fact that the electron transfer for this reaction is slightly exothermic $\left(\triangle G_{\text {et }}=-0.13\right.$ 


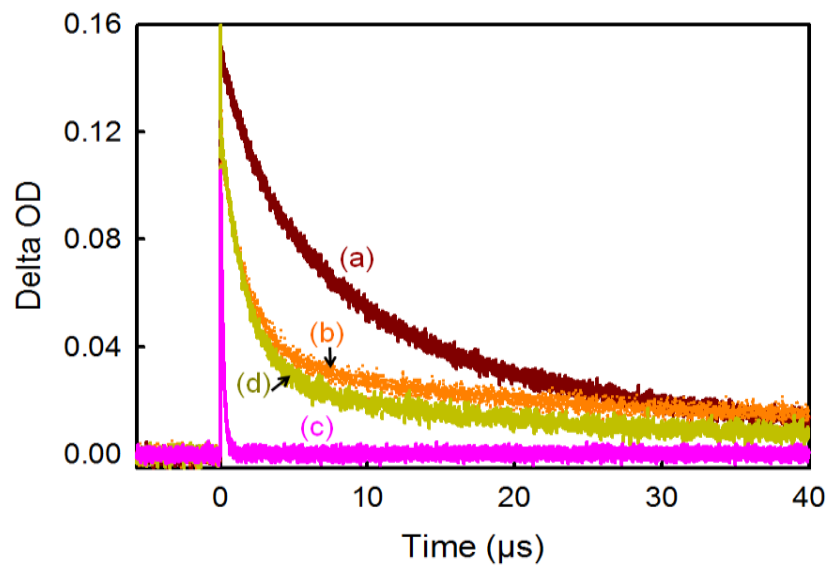

Figure 4. Decays of ${ }^{3} \mathrm{ITX}^{*}$ at $600 \mathrm{~nm}$ in the presence and absence of: (a) $\mathrm{IMesH}^{+} \mathrm{Cl}^{-}$, (b) $\mathrm{NaBPh}_{4}$, (c) $\mathrm{NaBPh}_{4}$ (under $\mathrm{O}_{2}$ ) and (d) $\mathrm{IMesH}^{+} \mathrm{BPh}_{4}^{-}\left([\mathrm{ITX}]=10^{-4} \mathrm{M}\right.$, $\left.\left[\mathrm{IMesH}^{+} \mathrm{Cl}\right]^{-}\right]=$ $\left[\mathrm{NaBPh}_{4}\right]=\left[\mathrm{IMesH}^{+} \mathrm{BPh}_{4}{ }^{-}\right]=6 \times 10^{-3} \mathrm{M}$, respectively, recorded in $\mathrm{N}_{2}$-saturated acetonitrile).

$\mathrm{eV}){ }^{21}$ because of the high oxidation potential of the donor anion $\mathrm{BPh}_{4}{ }^{-}$. Second, triplet energy transfer, which is the second possible interactions process between ITX $\left(E_{T}=2.77\right.$ $\mathrm{eV}$ ) and $\mathrm{BPh}_{4}{ }^{-}\left(\mathrm{E}_{\mathrm{T}}=3.64 \mathrm{eV}\right)$ (Fig. S1), is not energetically favorable. Third, our transition absorption spectrum strongly resembles that of thioxanthone radical anion observed by Schuster et al., who reported also a similar broad absorption at $650 \mathrm{~nm}^{36,37}$ To the best of our knowledge, the spectrum of $\mathrm{ITX}^{\boldsymbol{0}^{-}}$has not been previously reported. Because of the absorption overlap between ${ }^{3} \mathrm{ITX}^{*}$ and $\mathrm{ITX}^{--}$species, the quenching rate $\left(4.1 \times 10^{7} \mathrm{M}^{-1} \mathrm{~s}^{-1}\right)$ was obtained by analyzing only the first short component of the transient absorption decay. Additionally, the triplet transient of ITX in the presence of $\mathrm{BPh}_{4}{ }^{-}$was quickly quenched if an oxygen-saturated solution is used, with a typical rate constant in order of $10^{9} \mathrm{M}^{-1} \mathrm{~s}^{-1}$ (Figure 4, trace c). ${ }^{38,39}$ This lends additional confidence to the involvement of ${ }^{3}$ ITX* and the operation of a charge transfer mechanism. However, there is no additional band in the transient spectrum that might be attributed to the boranyl radical $\mathbf{4}$ or other boron species derived from the oxidation of tetraphenyl borate anion. In borate salts, it is well established that back electron is not significant but that boronyl radical can dissociate very rapidly and irreversibly (see next section). ${ }^{7}$ Therefore, the failure to observe $\mathrm{Ph}_{4} \mathrm{~B}^{\bullet}(4)$ indicates that a very short-lived character ${ }^{16}$ as this radical probably dissociates or rearranges during the laser pulse.

Having investigated the individual role of $\mathrm{IMesH}^{+}$and $\mathrm{BPh}_{4}^{-}$ , quenching experiment was then carried out using $\mathrm{IMesH}^{+} \mathrm{BPh}_{4}^{-}$(Figure 4, trace d). The similarity of quenching rate obtained by this quencher $\left(4.9 \times 10^{7} \mathrm{M}^{-1} \mathrm{~s}^{-1}\right)$ and $\mathrm{NaBPh}_{4}$ $\left(4.1 \times 10^{7} \mathrm{M}^{-1} \mathrm{~s}^{-1}\right)$ is well indicative that the photoreduction of ITX by $\mathrm{BPh}_{4}^{-}$is the primary photochemical process. Additionally, a broad feature characteristic of ITX ${ }^{-0}$ was also observed in the region of $560-680 \mathrm{~nm}$ (Fig. S2). However, there is no additional absorption band in the $380-430 \mathrm{~nm}$ region that could be assigned to a thioxanthyl ketyl radical $\mathbf{3}$ $\left(\mathrm{ITXH}^{\circ}\right)$ derived from subsequent proton transfer step of ITX with $\mathrm{IMesH}^{+}{ }^{29}$ This result can be understood on the basis of a much slower proton transfer step compared to electron
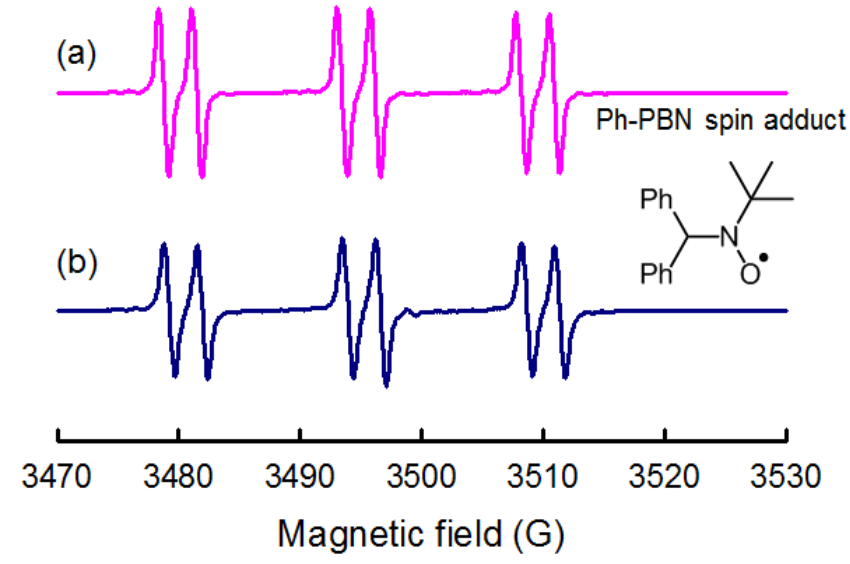

Figure 5. EPR spectra of radical adduct from a solution: (a) ITX $-\mathrm{NaBPh}_{4}-\mathrm{PBN}$ and (b) ITX - IMesH $\mathrm{BPPh}_{4}^{-}-\mathrm{PBN}$ after $60 \mathrm{~s}$ of irradiation. [ITX] $=5 \times 10^{-3} \mathrm{M}$, $\left[\mathrm{IMesH}^{+} \mathrm{BPh}_{4}{ }^{-}\right]=1.5 \times 10^{-2} \mathrm{M},\left[\mathrm{NaBPh}_{4}\right]=1.5 \times 10^{-2} \mathrm{M}$ and $[\mathrm{PBN}]=3 \times 10^{-3} \mathrm{M}$ in acetonitrile.

transfer. The only indication for protonation of the radical anion 1 is the shorter lifetime of $\mathrm{ITX}^{\circ-}$ in presence of $\mathrm{IMesH}^{+} \mathrm{BPh}_{4}^{-}(29.5 \mu \mathrm{s})$ compared to $\mathrm{NaBPh}_{4}(40.1 \mu \mathrm{s})$. A final quenching experiment was also carried out using IMes, the targeted NHC. A significant acceleration of the decay at 600 $\mathrm{nm}$ is observed, leading to an increased quenching rate $(7.2 \times$ $\left.10^{9} \mathrm{M}^{-1} \mathrm{~s}^{-1}\right)$. Such a result is consistent with the stronger donor properties of IMes $\left(E_{\mathrm{ox}}=-0.84 \mathrm{eV}\right)$ compared to $\mathrm{BPh}_{4}^{-}\left(\mathrm{E}_{\mathrm{ox}}=\right.$ $0.94 \mathrm{eV}) .^{22}$ It also highlights a more complex mechanism where photogenerated NHC can also interact with triplet ITX and compete with $\mathrm{BPh}_{4}{ }^{-}$for charge transfer.

\section{Electron paramagnetic resonance (EPR)}

As indicated in the previous section, failure to observe the boranyl radical (4) in the nanosecond experiment may indicate that this short-lived species dissociates very rapidly to give the phenyl radical (5) and triphenylborane (6). Spin trapping and EPR detection (with the trapping reagent $\alpha$-phenyl- $N$-tertbutylnitrone, PBN) were employed to detect the free radical $\mathrm{Ph}^{\bullet}$ formed during in situ irradiation of ITX in presence of tetraphenyl borate anion. In Figure 5, the experimental EPR spectra from ITX/NaBPh ${ }_{4} / \mathrm{PBN}$ (a) and ITX/IMesH ${ }^{+} \mathrm{BPh}_{4}{ }^{-} / \mathrm{PBN}$ (b) are shown. Similar in both instances, the EPR spectra show a strong triple-doublet signal suggestive of a single paramagnetic species and gradually increasing with irradiation time (see Fig. S3). Hyperfine coupling constants of the spin adduct that were retrieved from simulation $\left(a_{\mathrm{N}}=14.7 \mathrm{G}\right.$ and $a_{\mathrm{H}}=2.7 \mathrm{G}$, Fig. S4) are in agreement with a PBN spin adduct of the phenyl radical. In addition, these values correspond reasonably well to previously reported values for these spin adduct in literature. ${ }^{16,19}$ This result supports that the transition state of oxidized $\mathrm{BPh}_{4}{ }^{-}$could dissociate into $\mathrm{Ph}^{\bullet}$ and $\mathrm{Ph}_{3} \mathrm{~B} .{ }^{16,40}$ Moreover, it is noted that the detection of this phenyl radical 5 is generally very challenging, ${ }^{16}$ and failures are generally reported in the literature for both electrochemically ${ }^{7}$ and photochemically ${ }^{41}$ induced oxidation of $\mathrm{BPh}_{4}{ }^{-}$. By contrast, $\mathrm{n}$ butyl radical was more easily detected from a similar oxidation of $\mathrm{Ph}_{3} \mathrm{BBu}^{-}$species. $^{41}$ 


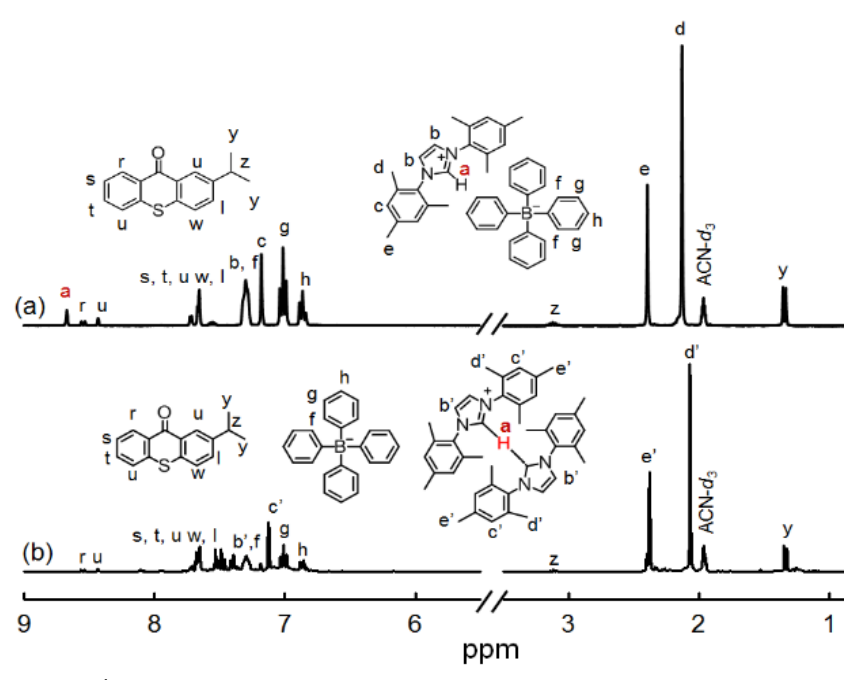

Figure 6. ${ }^{1} \mathrm{H}$ NMR spectra change of ITX $(0.07 \mathrm{M})$ and $\mathrm{IMesH}^{+} \mathrm{BPh}_{4}{ }^{-}(0.21 \mathrm{M})$ in ACN- $d_{3}$ : prior to UV exposure (a) and after 5 min irradiation (b).

\section{Assignment of photoproducts}

${ }^{1} \mathrm{H}$ and ${ }^{13} \mathrm{C}$ NMR spectroscopy

Using ${ }^{1} \mathrm{H}$ NMR spectroscopy, we found that irradiation of an oxygen-free acetonitrile- $d_{3}$ solution containing $\mathrm{IMesH}^{+} \mathrm{BPh}_{4}{ }^{-}$(1 equiv.) and ITX ( 3 equiv.) at $365 \mathrm{~nm}$ resulted in a complete deprotonation at $\mathrm{C} 2$ position $\left(\mathrm{H}_{a}, \delta=8.70 \mathrm{ppm}\right)$ of the imidazolium cation (Figure 6). ${ }^{21}$ This result clearly suggests the generation of IMes (2). Further evidence was given upon adding $\mathrm{CS}_{2}$ to the as-irradiated medium. A red precipitate forms immediately that was straightforwardly assigned to IMes- $\mathrm{CS}_{2}$ using ${ }^{1} \mathrm{H}$ and ${ }^{13} \mathrm{C}$ NMR analysis (Fig. S5). With these results and the identification of $\mathrm{ITX}^{\boldsymbol{0}^{-}}$described above, it is thus possible to formulate a tentative second step where NHC are created through proton abstraction of $\mathrm{IMesH}^{+}$cation by ITX $^{--}$(Figure 2). Two methods to determine NHC concentration that were described in previous publications (acid/base titration ${ }^{21}$ and ${ }^{1} \mathrm{H}$ NMR analysis of NHCcarbodiimide adduct ${ }^{22}$ ) revealed a similar $\mathrm{IMesH}^{+}$conversion of $50 \%$ after 5 min irradiation, which is in conflict with NMR data. A partial conversion means that IMes coexists in the reaction medium with its conjugated acid $\mathrm{IMesH}^{+}$and may form $\mathrm{H}$-bonded bis(carbene)-proton adduct. ${ }^{42-44}$ Formation of this $\mathrm{C} \cdots \mathrm{H}-\mathrm{C}$ type adduct has been already observed spectroscopically, e.g. UV, NMR. ${ }^{44}$ In our case, evidence for the formation of bis(carbene)-proton adduct is reflected by the slight shift to lower resonance of methylene protons $\mathrm{H}_{e^{\prime}}(\delta$ $=2.07 \mathrm{ppm})$ and $\mathrm{H}_{d^{\prime}}(\delta=2.37 \mathrm{ppm})$ observed after irradiation (trace b) compared to the initial state (trace a). Similar upfield shift was evidenced when adding 1 equiv. of free IMes to 9 equiv. of $\mathrm{IMesH}^{+} \mathrm{BPh}_{4}{ }^{-}$(Fig. S6). In this spectrum, the bridging proton $\mathrm{H}_{a}(\delta=8.70 \mathrm{ppm})$ of the $\mathrm{C} \cdots \mathrm{H}-\mathrm{C}$ complex disappeared entirely due to $\mathrm{H}$-bonding. This confirms that protonation degree cannot be used to quantitatively assess the NHC yield.

\section{GC-MS}

To move forward in the identification of other photoproducts, the freshly irradiated photolysis medium was analyzed by GC-MS. Three products were detected: biphenyl,

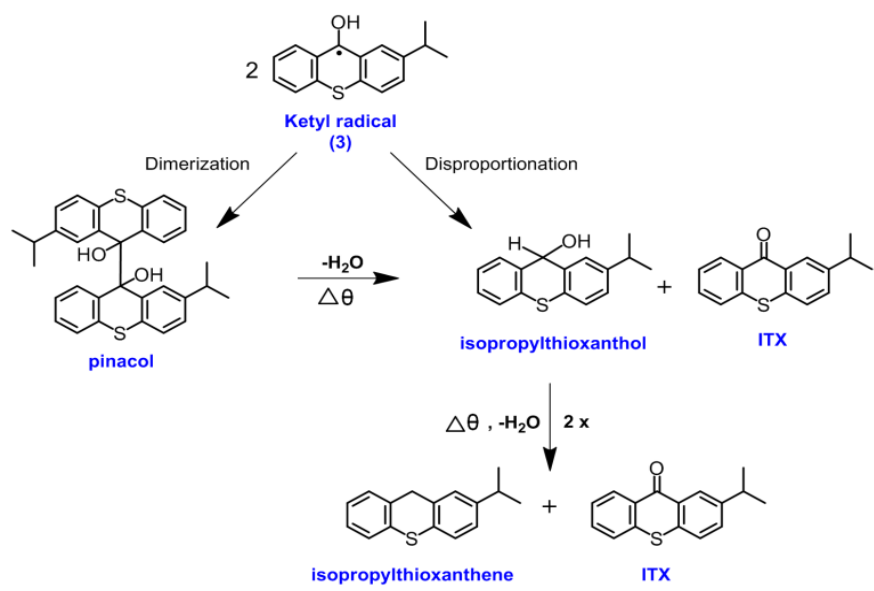

Figure 7. Side-reactions involving ITX ketyl radical.

isopropylthioxanthene and ITX (Fig. S7 and Table S1). Biphenyl was obtained in good yield and its formation was also observed in other (photo)oxidation experiments of $\mathrm{BPh}_{4}^{-}$ anion by iron (II) complex, $^{40} 1,4$-dicyanonaphthalene ${ }^{7}$ or coumarin derivative. ${ }^{41}$ However, the formation of biphenyl upon coupling of phenyl radical (detected by EPR) is unlikely. Labelling studies ${ }^{7,41}$ revealed indeed that two phenyl groups of the biphenyl come from the same borate, suggesting that the biphenyl was formed from carbons that were bound to boron. It is therefore reasonable to assume that biphenyl comes from triphenylborane. The most plausible explanation is that $\mathrm{Ph}^{\circ}$ reacts rapidly with $\mathrm{Ph}_{3} \mathrm{~B}$ to produce $\mathrm{Ph}-\mathrm{Ph}$ and $\mathrm{Ph}_{2} \mathrm{~B} \cdot{ }^{\circ 0}$ The fate of the boron radical will be discussed in the ${ }^{11} B N M R$ section. Since it does not require the addition of oxygen in the reaction medium, biphenyl is thus a primary photochemical product.

In contrast, isopropylthioxanthene and ITX result from the ensuing ground-state chemistry and might derive from ITXH (3), the thioxanthyl ketyl radical that is formed after the protonation process of $\mathrm{ITX}^{\circ-}$, and that we were not able to detect by nanosecond spectroscopy. As described in Figure 7, the ketyl radical $\mathbf{3}$ may undergo two types of reaction: first, a disproportionation, giving ITX and isopropylthioxanthol; ${ }^{45,46}$ second, a dimerization leading to dithioxanthyl pinacol derivative. ${ }^{47}$ However, except ITX, none of these thioxanthone reduction products were detected by GC-MS. This is apparently due to their thermal instability in the GC injection port as established by Schuster et al. ${ }^{36}$ Isopropylthioxanthol is known to disproportionate upon heating to form ITX and isopropylthioxanthene. Additionally, pinacol can be easily oxidized under air to regenerate ITX. ${ }^{36,46}$ This set of reactions is consistent with the formation of ketyl radical 3 and the thioxanthone products detected in GC-MS. Note also that 1phenyl-1,4-cyclohexadiene is not detected while it is a major product of the direct photolysis of $\mathrm{BPh}_{4}{ }^{-}$in presence of $\mathrm{H}$ donors. ${ }^{1}$ Its absence confirms that energy transfer from ITX to $\mathrm{BPh}_{4}{ }^{-}$is not the predominant mechanism. 


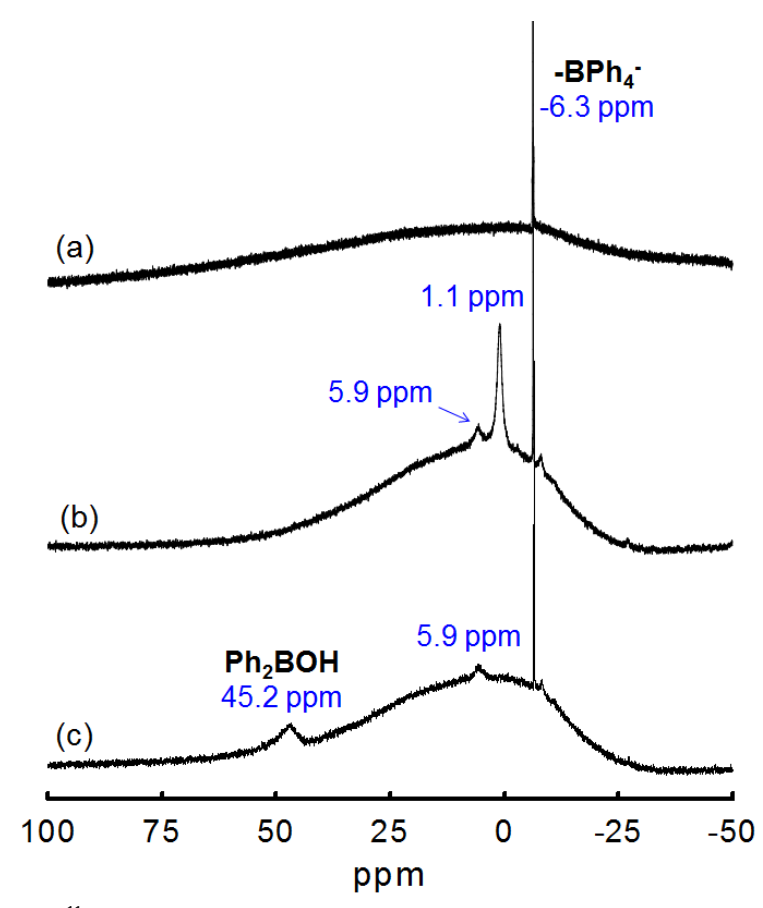

Figure 8. ${ }^{11} \mathrm{~B}-\mathrm{NMR}$ spectra of a mixture of ITX $(0.03 \mathrm{M})$ and $\mathrm{IMesH}^{+} \mathrm{BPh}_{4}{ }^{-}(0.03 \mathrm{M})$ in THF- $d_{8}$ : (a) prior irradiation, (b) after $10 \mathrm{~min}$ UV exposure, and (c) after adding $\mathrm{CS}_{2}$ into medium. Irradiation conditions: LED $365 \mathrm{~nm}, 65 \mathrm{~mW} \cdot \mathrm{cm}^{-2}$.

\section{${ }^{11}$ B NMR spectroscopy}

In arylboron photochemistry, the identification of boron photoproducts represents a major challenge. Boron products can be involved in complex reactions where both the nature and the role of the boron species can be hard to determine. Additionally, their proportion generally differ depending on whether irradiation was performed under $\mathrm{N}_{2}$ or air. As emphasized in Figure 2, the oxidized borate is assumed to evolve in triphenylborane, ${ }^{16,21,48,49}$ with possibly subsequent degradation reactions. ${ }^{40}$ In our case, the photogenerated $\mathrm{Ph}_{3} \mathrm{~B}$ could for example form ate-complexes with the photogenerated NHC Lewis base. ${ }^{50,51}{ }^{11} \mathrm{~B}$ NMR spectroscopy remains the best tool to identify the boron species. In the case of photoinitiated oxidation of arylborates, the NMR identification has rarely been studied, ${ }^{7,52}$ while it can serve to provide insights into the mechanism. Nevertheless, precise identification of the groups attached to boron is not trivial owing to the limited structural information that can be derived from ${ }^{11} \mathrm{~B}$ NMR data.

Figure 8 shows the ${ }^{11} \mathrm{~B}$ NMR spectrum of an argon saturated solution of $\mathrm{ITX} / \mathrm{IMesH}^{+} \mathrm{BPh}_{4}^{-}$(1/1 equiv.) prior (a) and after $10 \mathrm{~min}$ irradiation (b). As expected, spectrum a exhibits only a narrow singlet attributed to $\mathrm{BPh}_{4}{ }^{-}$anion $(\delta=-$ $6.3 \mathrm{ppm})$. This chemical shift is characteristic of tetraorganoborate anions experiencing a strong deshielding. In the spectrum b obtained after irradiation, the residual resonance of $\mathrm{BPh}_{4}{ }^{-}$is visible as well as two new features: an intense peak at $1.1 \mathrm{ppm}$, and a broad and much weaker signal at $5.9 \mathrm{ppm}$. Acting on the assumption that these species might derive from triphenylborane (6), a set of experiments using $\mathrm{BPh}_{3}$ was implemented. The ${ }^{11} \mathrm{~B}$ NMR spectrum of $\mathrm{Ph}_{3} \mathrm{~B}$ (shown in Fig. S8) reveals a single and characteristic singlet at

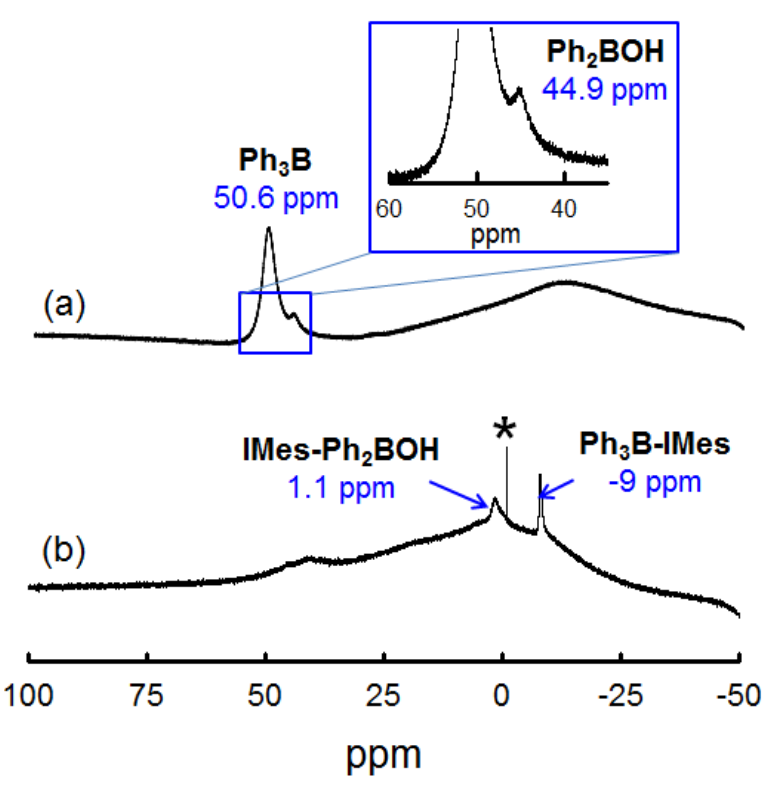

Figure 9. ${ }^{11} \mathrm{~B}-\mathrm{NMR}$ spectra in non-dried THF- $\mathrm{d}_{8}$ : (a) Hydrolyzed $\mathrm{Ph}_{3} \mathrm{~B}$, (b) Addition of IMes into hydrolyzed $\mathrm{Ph}_{3} \mathrm{~B}$. The asterisk is used to designate an impurity of IMes.

$50.3 \mathrm{ppm}$ that is absent in the photolysis medium. In addition, the irradiation of $\mathrm{Ph}_{3} \mathrm{~B}$ with or without ITX (1 equiv.) did not cause any change in the spectrum. In contrast, the addition of IMes (1 equiv.) resulted in the formation of a white precipitate and a downfield chemical shift ( -9 ppm, see Fig. S9) characteristic of NHC-borane species, that was not observed in spectrum $\mathbf{b}$. Though the above experiments do not necessarily demonstrate that $\mathrm{Ph}_{3} \mathrm{~B}$ has not been formed, it is interesting to note that both free $\mathrm{Ph}_{3} \mathrm{~B}$ or $\mathrm{Ph}_{3} \mathrm{~B}$-IMes adducts are not present in the photolysis medium, and that degradation reaction with triplet excited ITX cannot be advanced as explanation. As hypothesized in the last section, it is thus more reasonable to conclude that $\mathrm{Ph}_{3} \mathrm{~B}$ may react with $\mathrm{Ph}^{\bullet}$ to form $\mathrm{Ph}_{2} \mathrm{~B}^{\circ}$.

To shed further light into the identity of these boroncontaining species, $\mathrm{CS}_{2}$ was added to the photolysate solution $\left(\mathrm{ITX} / \mathrm{IMesH}^{+} \mathrm{BPh}_{4}{ }^{-}\right.$) just after irradiation (Figure 8, spectrum c). This led to immediate conversion of the intermediate at 1.1 ppm to a new broad resonance at $45.2 \mathrm{ppm}$ while the position of the second resonance at $5.9 \mathrm{ppm}$ remained unchanged. The change of chemical shift suggests that a NHC-borane species was initially present. The addition of $\mathrm{CS}_{2}$ caused its

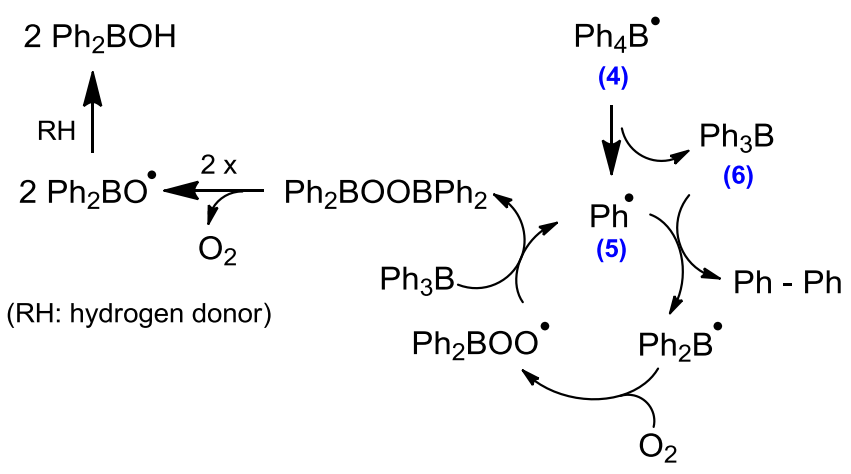

Figure 10. Mechanism accounting for the formation of diphenylborinic acid $\left(\mathrm{Ph}_{2} \mathrm{BOH}\right)$. 
dissociation and the subsequent formation of the more stable $\mathrm{IMes}_{-} \mathrm{CS}_{2}$ zwitterionic adduct. By this means, a free boron species was released whose value of ${ }^{11} \mathrm{~B}$ chemical shift at 45.2 ppm can be useful for its assignment. Observed ${ }^{53}$ and calculated ${ }^{11} \mathrm{~B}$ NMR spectra ${ }^{54}$ are consistent with the exact chemical shift of diphenylborinic acid $\mathrm{Ph}_{2} \mathrm{BOH}$. Consequently, the singlet signal at $1.1 \mathrm{ppm}$ could be ascribed to IMes$\mathrm{Ph}_{2} \mathrm{BOH}$ adduct present in the photolysis solution. However, the second weak signal at $5.9 \mathrm{ppm}$ could not be assigned. Notably, this second boron-containing complex is not able to form ate-complex with IMes due to the absence of change in the chemical resonance when $\mathrm{CS}_{2}$ is introduced. To provide further evidence for this assignment, $\mathrm{Ph}_{2} \mathrm{BOH}$ was generated in situ by moderate hydrolysis of the $\mathrm{Ph}_{3} \mathrm{~B}$ in non-dried THF- $d_{8}$ upon exposing the solution in the NMR tube to atmosphere. ${ }^{55}$ This solution revealed two broad signals centered at $44.9 \mathrm{ppm}$ $\left(\mathrm{Ph}_{2} \mathrm{BOH}\right)$ and $50.6 \mathrm{ppm}$ (residual $\mathrm{Ph}_{3} \mathrm{~B}$ ) in the ${ }^{11} \mathrm{~B}$ NMR spectrum (Figure 9). Addition of IMes into the medium caused the two signals to shift at $-9 \mathrm{ppm}\left(\mathrm{Ph}_{3} \mathrm{~B}\right.$-IMes adduct) and 1.1 ppm (IMes- $\mathrm{Ph}_{2} \mathrm{BOH}$ adduct). This latter is visible in the spectrum b of Figure 8, lending further confidence in our assignment. The last issue to be settled concerns the mechanism leading to the formation of $\mathrm{Ph}_{2} \mathrm{BOH}$. As described in Figure 10, we postulate that the formation of $\mathrm{Ph}_{2} \mathrm{BOH}$ may relate to the autooxidation of $\mathrm{Ph}_{3} \mathrm{~B}$ species. Reaction of $\mathrm{Ph}_{3} \mathrm{~B}$ with $\mathrm{Ph}^{\bullet}$ yields $\mathrm{Ph}_{2} \mathrm{~B}^{\bullet}$ and $\mathrm{Ph}_{2}$. $\mathrm{Ph}_{2} \mathrm{~B}^{\bullet}$ can react subsequently with traces of oxygen (even if argon purged NMR tube were used) to form the peroxyl radical $\mathrm{Ph}_{2} \mathrm{BOO}$. New reaction with $\mathrm{Ph}_{3} \mathrm{~B}$ might form the peroxide species $\mathrm{Ph}_{2} \mathrm{BOOBPh}_{2}$, easily decomposed in $\mathrm{Ph}_{2} \mathrm{BO}$. $\mathrm{Ph}_{2} \mathrm{BOH}$ could be formed by hydrogen abstraction with proton donor or after hydrolysis with water.

\section{Conclusions}

The photochemical mechanism underlying the release of $\mathrm{NHC}$ upon irradiation of $\mathrm{IMesH}^{+} \mathrm{BPh}_{4}{ }^{-}$with ITX has been clarified. As summarized in Figure 11, the first step is an electron transfer $\left(k_{\mathrm{q}}=4.9 \times 10^{7} \mathrm{M} \cdot \mathrm{s}^{-1}\right)$ between electronically excited ITX and borate anion $\mathrm{BPh}_{4}{ }^{-}$acting as electron donor to yield the ion pair $\mathrm{IMesH}^{+} / \mathrm{ITX}^{\circ-}$ and the boranyl radical $\mathrm{Ph}_{4} \mathrm{~B}^{\circ}$. This latter is subjected to a rapid decomposition into $\mathrm{Ph}^{\bullet}$ and $\mathrm{Ph}_{3} \mathrm{~B}$. A subsequent reaction of the ion pair is proton abstraction of $\mathrm{IMesH}^{+}$by ITX ${ }^{--}$to form the IMes (NHC) and the ketyl radical $\left(\mathrm{ITXH}^{\circ}\right)$. Of high importance for $\mathrm{NHC}$ reactivity was the fate of organoboron products. $\mathrm{Ph}_{3} \mathrm{~B}$ and $\mathrm{Ph}^{\bullet}$ were proved to undergo a multi-step oxidation reaction, yielding biphenyl and diphenylborinic acid. $\mathrm{Ph}_{2} \mathrm{BOH}$ was found to react with the photogenerated IMes to give an $\mathrm{IMes}-\mathrm{Ph}_{2} \mathrm{BOH}$ ate-complex. While it is difficult to avoid the formation of NHC-boron adduct, our recent investigation showed that such complex did not prevent the activity of its NHC photogenerator in ringopening methathesis polymerization or for synthesis of polyurethane, ${ }^{22}$ but could have a detrimental effect on other reactions. Knowledge about the precise photochemical mechanism offers now the possibility for improving the photoinitiating system in a rational way, and create a new generation of NHC photogenerator.

\section{Conflicts of interest}

There are no conflicts to declare.

\section{Acknowledgements}

Financial support by French National Research Agency (ANR program: DS0304 2016, contract number: ANR-16-CE07-0016) is gratefully acknowledged.<smiles>CC(C)c1ccc2sc3ccccc3c(=O)c2c1</smiles>
ITX

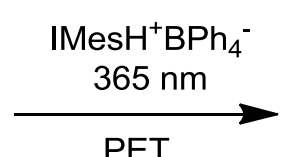
PET
$1 / 4$<smiles>CC(I)c1ccc2c(c1)Cc1ccccc1S2</smiles>
Isopropylthioxanthene<smiles>CC(I)c1ccc2c(c1)C([O-])c1ccccc1S2</smiles>

(1)

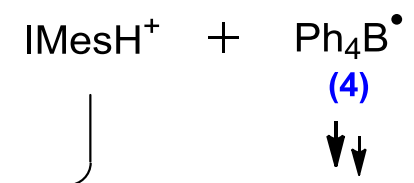

$\mathrm{Ph}_{3} \mathrm{~B}+\mathrm{Ph}^{\circ}$

(6)

(5)

$\downarrow \downarrow$ decomposition<smiles>CC(I)c1ccc2c(c1)C(O)c1ccccc1S2</smiles>
$\mathrm{Ph}_{2} \mathrm{BOH}+\mathrm{Ph}_{2}$

(3)

$3 / 4$<smiles>CC(C)c1ccc2sc3ccccc3c(=O)c2c1</smiles>

(2)

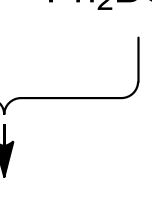

IMes $-\mathrm{Ph}_{2} \mathrm{BOH}$ adduct

Figure 11. General mechanistic pathway involved in the formation of IMes during the photolysis of a mixture ITX/IMesH ${ }^{+} \mathrm{BPh}_{4}{ }^{-}$ 


\section{Notes and references}

1 J. L. R. Williams, J. C. Doty, P. J. Grisdale, R. Searle, T. H. Regan, G. P. Happ and D. P. Maier, Boron photochemistry. I. Irradiation of sodium tetraarylborates in aqueous solution, $J$. Am. Chem. Soc., 1967, 89, 5153-5157.

2 A. Pelter, R. T. Pardasani and P. Pardasani, The Photochemistry of Boron Compounds, Tetrahedron, 2000, 56 7339-7369.

3 J. Radtke, S. K. Mellerup, M. Bolte, H.-W. Lerner, S. Wang and M. Wagner, Aryl Insertion vs Aryl-Aryl Coupling in C,CChelated Organoborates: The "Missing Link" of Tetraarylborate Photochemistry, Org. Lett., 2018, 20, 3966-3970.

4 W. G. Santos, J. Pina, D. H. Burrows, M. D. E. Forbes and D. R. Cardoso, New insight into the photophysics and reactivity of trigonal and tetrahedral arylboron compounds, Photochem. Photobiol. Sci., 2016, 15, 1124-1137.

5 T. Baumgartner and F. Jaekle, Main Group Strategies Towards Functional Hybrid Materials, John Wiley \& Sons, New Jersey, 2018, pp. 87-92.

6 X. Sun, J. P. Gao and Z. Y. Wang, Bicyclic Guanidinium Tetraphenylborate: A Photobase Generator and A Photocatalyst for Living Anionic Ring-Opening Polymerization and CrossLinking of Polymeric Materials Containing Ester and Hydroxy Groups, J. Am. Chem. Soc., 2008, 130, 8130-8131.

7 J. D. Wilkey and G. B. Schuster, Irradiation of tetraphenylborate does not generate a borene anion, J. Org. Chem., 1987, 52, 2117-2122.

8 J. L. R. Williams, J. C. Doty, P. J. Grisdale, T. H. Regan, G. P. Happ and D. P. Maier, Boron photochemistry. II. Irradiation of sodium tetraarylborates in alcohol solutions, J. Am. Chem. Soc. 1968, 90, 53-55.

9 Y. H. Zhao, D. Vuluga, L. Lecamp and F. Burel, Photoinitiated thiol-epoxy addition for the preparation of photoinduced selfhealing fatty coatings, RSC Adv., 2016, 6, 32098-32105.

10 Y. Jian, Y. He, Y. Sun, H. Yang, W. Yang and J. Nie, Thiolepoxy/thiol-acrylate hybrid materials synthesized by photopolymerization, J. Mater. Chem. C, 2013, 1, 4481.

11 S. Chatani, T. Gong, B. A. Earle, M. Podgórski and C. N. Bowman, Visible-Light Initiated Thiol-Michael Addition Photopolymerization Reactions, ACS Macro Lett., 2014, 3, 315318.

12 J. Shin, H. Matsushima, C. M. Comer, C. N. Bowman and C. E. Hoyle, Thiol-Isocyanate-Ene Ternary Networks by Sequentia and Simultaneous Thiol Click Reactions, Chem. Mater., 2010, 22, 2616-2625.

13 D. Perrot, C. Croutxé-Barghorn and X. Allonas, UV-curable thio-ether-urethane network with tunable properties, J. Polym Sci. Part A: Polym. Chem., 2016, 54, 3119-3126.

14 S. Murphy and G. B. Schuster, A Kinetic Method for Determination of Redox Potentials: Oxidation of Tetraarylborates, J. Phys. Chem., 1995, 99, 511-515.

15 S. Chatterjee, P. D. Davis, P. Gottschalk, M. E. Kurz, B. Sauerwein, X. Yang and G. B. Schuster, Photochemistry of carbocyanine alkyltriphenylborate salts: intra-ion-pair electron transfer and the chemistry of boranyl radicals, J. Am. Chem. Soc., 1990, 112, 6329-6338.

16 T. Konishi, Y. Sasaki, M. Fujitsuka, Y. Toba, H. Moriyama and O. Ito, Persistent C60 anion-radical formation via photoinduced electron transfer from tetraphenylborate and triphenylbutylborate, J. Chem. Soc. Perkin Trans. 2, 1999, 3, 551-556.

17 R. Popielarz, A. M. Sarker and D. C. Neckers, Applicability of Tetraphenylborate Salts as Free Radical Initiators, Macromolecules, 1998, 31, 951-954.

18 A. Y. Polykarpov, S. Hassoon and D. C. Neckers, Tetramethylammonium Tetraorganylborates as Coinitiators with
5,7-Diiodo-3-butoxy-6-fluorone in Visible Light Polymerization of Acrylates, Macromolecules, 1996, 29, 8274-8276.

19 S. Hassoon, A. Sarker, A. Y. Polykarpov, M. A. J. Rodgers and D. C. Neckers, Photoinduced Inter- and Intra-Ion-Pair Electron Transfer Reactions in N-(p-Benzoylbenzyl)-N,N,N-tri-nbutylammonium Triphenyl-n-butylborate and -Gallate Salts, J. Phys. Chem., 1996, 100, 12386-12393.

$20 \mathrm{~J}$. Y. Lan and G. B. Schuster, Photoalkylation of dicyanoarenes with alkyltriphenylborate salts, J. Am. Chem. Soc., 1985, 107, 6710-6711.

21 J. Pinaud, T. K. H. Trinh, D. Sauvanier, E. Placet, S. Songsee, P. Lacroix-Desmazes, J.-M. Becht, B. Tarablsi, J. Lalevée, L. Pichavant, V. Héroguez and A. Chemtob, In Situ Generated Ruthenium-Arene Catalyst for Photoactivated Ring-Opening Metathesis Polymerization through Photolatent N-Heterocyclic Carbene Ligand, Chem. Eur. J., 2018, 24, 337-341.

22 T. K. H. Trinh, J. P. Malval, F. Morlet-Savary, J. Pinaud, P. Lacroix-Desmazes, C. Reibel, V. Héroguez and A. Chemtob, Mixture of azolium tetraphenylborate with isopropylthioxanthone: a new class of $\mathrm{N}$-heterocyclic carbene (NHC) photogenerator for polyurethane, polyester and ROMP polymers synthesis, Chem. Eur. J., 2019, DOI: doi.org/10.1002/chem.201901000.

23 M. Scholl, S. Ding, C. W. Lee and R. H. Grubbs, Synthesis and Activity of a New Generation of Ruthenium-Based Olefin Metathesis Catalysts Coordinated with 1,3-Dimesityl-4,5dihydroimidazol-2-ylidene Ligands, Org. Lett., 1999, 1, 953-956. 24 N. E. Kamber, W. Jeong, S. Gonzalez, J. L. Hedrick and R. M Waymouth, N-Heterocyclic Carbenes for the Organocatalytic Ring-Opening Polymerization of $\varepsilon$-Caprolactone, Macromolecules, 2009, 42, 1634-1639.

25 J. Raynaud, W. N. Ottou, Y. Gnanou and D. Taton, Metal-free and solvent-free access to $\alpha, \omega$-heterodifunctionalized poly(propylene oxide)s by $\mathrm{N}$-heterocyclic carbene-induced ring opening polymerization, Chem. Commun., 2010, 46, 3203.

26 B. Bantu, G. M. Pawar, U. Decker, K. Wurst, A. M. Schmidt and M. R. Buchmeiser, $\mathrm{CO}_{2}$ and $\mathrm{Sn}^{\prime \prime}$ Adducts of $\mathrm{N}$-Heterocyclic Carbenes as Delayed-Action Catalysts for Polyurethane Synthesis, Chem. Eur. J., 2009, 15, 3103-3109.

27 S. Naumann, F. G. Schmidt, W. Frey and M. R. Buchmeiser, Protected $\mathrm{N}$-heterocyclic carbenes as latent pre-catalysts for the polymerization of $\varepsilon$-caprolactone, Polym. Chem., 2013, 4, 4172.

28 J. Zhang, N. Pidlypnyi, M. Nieger, J. C. Namyslo and A. Schmidt, Zwitterionic borane adducts of $\mathrm{N}$-heterocyclic carbenes from mesomeric betaines of uracil, Org. Biomol. Chem., 2014, 12, 2737-2744.

29 V. Charlot, A. Ibrahim, X. Allonas, C. Croutxé-Barghorn and C. Delaite, Photopolymerization of methyl methacrylate: effects of photochemical and photonic parameters on the chain length, Polym. Chem., 2014, 5, 6236-6243.

30 J. Christmann, X. Allonas, C. Ley, A. Ibrahim and C. CroutxéBarghorn, Triazine-Based Type-II Photoinitiating System for Free Radical Photopolymerization: Mechanism, Efficiency, and Modeling, Macromol. Chem. Phys., 2017, 218, 1600597.

31 J. Christmann, S. Shi, A. Ibrahim, C. Ley, C. Croutxé-Barghorn, $M$. Bessières and $X$. Allonas, Mechanistic Investigation of a Dual Bicyclic Photoinitiating System for Synthesis of OrganicInorganic Hybrid Materials, J. Phys. Chem. B, 2017, 121, 19721981.

32 A. Allushi, C. Kutahya, C. Aydogan, J. Kreutzer, G. Yilmaz and Y. Yagci, Conventional Type II photoinitiators as activators for photoinduced metal-free atom transfer radical polymerization, Polym. Chem., 2017, 8, 1972-1977.

33 X. Allonas, C. Ley, C. Bibaut, P. Jacques and J. P. Fouassier Investigation of the triplet quantum yield of thioxanthone by time-resolved thermal lens spectroscopy: solvent and population lens effects, Chem. Phys. Lett., 2000, 322, 483-490. 
34 E. Andrzejewska, D. Zych-Tomkowiak, M. Andrzejewski, G. L. Hug and B. Marciniak, Heteroaromatic Thiols as Co-initiators for Type II Photoinitiating Systems Based on Camphorquinone and Isopropylthioxanthone, Macromolecules, 2006, 39, 3777-3785.

$35 \mathrm{H}$. Shizuka and H. Obuchi, Anion-induced triplet quenching of aromatic ketones by nanosecond laser photolysis, J. Phys. Chem., 1982, 86, 1297-1302.

36 S. F. Yates and G. B. Schuster, Photoreduction of triplet thioxanthone by amines: charge transfer generates radicals that initiate polymerization of olefins, J. Org. Chem., 1984, 49, 33493356.

37 J. C. Scaiano, Intermolecular photoreductions of ketones, J. Photochem., 1973, 2, 81-118.

38 Amirzadeh, G. and Schnabel, W., On the photoinitiation of free radical polymerization-laser flash photolysis investigations on thioxanthone derivatives, Makromol Chem, 1981, 182, 28212835.

39 M. Aydin, N. Arsu, Y. Yagci, S. Jockusch and N. J. Turro, Mechanistic Study of Photoinitiated Free Radical Polymerization Using Thioxanthone Thioacetic Acid as One-Component Type II Photoinitiator, Macromolecules, 2005, 38, 4133-4138.

40 Y. Nishida, Y.-M. Lee, W. Nam and S. Fukuzumi, Autocatalytic Formation of an Iron(IV)-Oxo Complex via Scandium IonPromoted Radical Chain Autoxidation of an Iron(II) Complex with Dioxygen and Tetraphenylborate, J. Am. Chem. Soc., 2014 136, 8042-8049.

41 A. M. Sarker, Y. Kaneko and D. C. Neckers, Photochemistry and photophysics of novel photoinitiators: $\mathrm{N}, \mathrm{N}, \mathrm{N}$-tributyl-N-(4methylene-7-methoxycoumarin) ammonium borates, J. Photochem. Photobiol. Chem., 1998, 117, 67-74.

42 O. Hollóczki, Unveiling the peculiar hydrogen bonding behavior of solvated N-heterocyclic carbenes, Phys. Chem. Chem. Phys., 2016, 18, 126-140.

43 M. Thomas, M. Brehm, O. Hollóczki and B. Kirchner, How Can a Carbene be Active in an Ionic Liquid?, Chem. Eur. J., 2014, 20, 1622-1629.

44 A. J. I. Arduengo, S. F. Gamper, M. Tamm, J. C. Calabrese, F. Davidson and H. A. Craig, A Bis(carbene)-Proton Complex: Structure of a C-H-C Hydrogen Bond, J. Am. Chem. Soc., 1995, 117, 572-573.

45 S. Dadashi-Silab, C. Aydogan and Y. Yagci, Shining a light on an adaptable photoinitiator: advances in photopolymerizations initiated by thioxanthones, Polym. Chem., 2015, 6, 6595-6615.

46 F. G. Kny-Jones and A. M. Ward, LXXVI.-Investigations on the bivalency of carbon. Part III. Some experiments on xanthhydrol, dixanthhydryl ether, and xanthhydryl chloride, J. Chem. Soc., 1930, 0, 535-542.

47 W. A. Green, Industrial Photoinitiators: A Technical Guide, CRC Press, Boca Raton, $1^{\text {st }}$ edn, 2010, pp. 69-70.

48 S. T. Murphy, C. Zou, J. B. Miers, R. M. Ballew, D. D. Dlott and G. B. Schuster, Tetraarylborates $\{[\mathrm{Ar}] 4 \mathrm{~B}-\}$ : estimation of oxidation potentials and reorganization energies from electrontransfer rates, J. Phys. Chem., 1993, 97, 13152-13157.

49 B. P. Sullivan, W. J. Dressick and T. J. Meyer, Photoelectrochemical cell based on the ion pair 1,1'-dimethyl4,4'-bipyridinium bis(tetraphenylborate). Photocurrents from the direct irradiation of a donor-acceptor complex, J. Phys. Chem., 1982, 86, 1473-1478.

50 P. A. Chase, A. L. Gille, T. M. Gilbert and D. W. Stephan, Frustrated Lewis pairs derived from $\mathrm{N}$-heterocyclic carbenes and Lewis acids, Dalton Trans., 2009, 35, 7179-7188.

51 P. A. Chase and D. W. Stephan, Hydrogen and Amine Activation by a Frustrated Lewis Pair of a Bulky N-Heterocyclic Carbene and B(C6F5)3, Angew. Chem. Int. Ed., 2008, 47, 74337437.

52 J. J. Eisch, J. H. Shah and M. P. Boleslawski, Skeletal rearrangements of arylborane complexes mediated by redox reactions: thermal and photochemical oxidation by metal ions, $J$. Organomet. Chem., 1994, 464, 11-21.

53 S. Arkhipenko, Approaches to Novel B-N Chemistry at the Boundary of Frustrated Lewis Pairs and Bifunctional Catalysis, PhD Thesis Durh. Univ., 2017, E-Thesis Online. DOI: 10.15128/et0012213.

54 H. S. Rzepa, S. Arkhipenko, E. Wan, M. T. Sabatini, V. Karaluka, A. Whiting and T. D. Sheppard, An Accessible Method for DFT Calculation of 11B NMR Shifts of Organoboron Compounds, J. Org. Chem., 2018, 83, 8020-8025.

$55 \mathrm{~N}$. Miyaura, in Science of Synthesis: Houben-Weyl Methods of Molecular Transformations, ed. D. E. Kaufmann and D. S. Matteson, Georg Thieme Verlag, Stuttgart, $1^{\text {st }}$ edn, 2014, vol. 6, pp. 677-678. 